\title{
Desenvolvimento de um creme de laranja e avaliação da qualidade físico-química, microbiológica e sensorial
}

\author{
Heloisa Schuck ${ }^{1}$ \\ Paula Andressa Fischer ${ }^{1}$ \\ Valeriano Antônio Corbellini ${ }^{2}$ \\ Ana Lúcia Becker Rolhfes ${ }^{2}$ \\ Nádia de Monte Baccar ${ }^{2}$ \\ Liliane Marquardt ${ }^{3}$ \\ Mari Silvia Rodrigues de Oliveira ${ }^{4}$
}

\section{RESUMO}

O objetivo deste trabalho foi desenvolver uma formulação alimentícia de creme de laranja com controle de qualidade adequado, avaliar sua aceitabilidade sensorial e determinar o valor nutricional para que este possa ser utilizado com fins comerciais em padarias e confeitarias. Para a formulação do creme foram utilizadas laranjas Valência (Citrus sinensis), açúcar, gemas, gelatina em pó incolor, manteiga e creme de leite. Foi empregado um processo térmico de pasteurização em banho-maria com variações de tempo e temperatura. As análises da composição proximal do creme de laranja foram realizadas segundo metodologia preconizada pelo Instituto Adolfo Lutz (2008) e o valor calórico segundo Lehninger (2011). A análise sensorial foi realizada através de ficha de análise de atributos. As contagens de Estafilococos Coagulase positiva e de Coliformes Termotolerantes $45^{\circ} \mathrm{C}$ encontraram-se dentro dos limites estabelecidos pela legislação vigente. Não foi detectada a presença de Salmonella. Encontrou-se um índice de 44,30\% de umidade, $0,36 \%$ de cinzas, $29,68 \%$ de lipídeos , 1,68\% de fibras, $13,02 \%$ de proteínas, $10,95 \%$ de carboidratos e um total de $366,42 \mathrm{kcal} / 100 \mathrm{~g}$. O Índice de Aceitabilidade (IA) para a impressão global foi superior a $70 \%$, aferindo a este produto uma aceitação sensorial satisfatória.

Palavras-chave: Creme de laranja. Qualidade Físico-química. Avaliação microbiológica. Análise sensorial.

\section{ABSTRACT}

The aim of this study was to develop an orange cream dietary formulation with appropriate quality control, evaluate it's sensory acceptability and determine the nutritional value so that it can be used for commercial purposes in bakeries and pastry shops. For the cream formulation were used Valencia oranges (Citrus sinensis), sugar, egg yolks, gelatin colorless powder, butter and sour cream. It was used a thermal pasteurization process in a water bath with time and temperature variations.

\footnotetext{
${ }^{1}$ Alunas do curso de Nutrição da Universidade de Santa Cruz do Sul - UNISC. 2Professores do Departamento de Química e Física na Universidade de Santa Cruz do Sul. 3Professora do Departamento de Engenharia, Arquitetura e Ciências Agrárias na Universidade de Santa Cruz do Sul.

${ }^{4}$ Doutora em Ciência e Tecnologia de Alimentos, Universidade Federal de Santa Maria - UFSM. <marisilviadeoliveira@yahoo.com.br>
} 
The analysis of the proximal composition of orange cream were made according to the methodology recommended by the Adolfo Lutz Institute (2008) and the caloric value according to Lehninger (2011). Sensory analysis was performed using attributes analysis spreadsheet. The positive coagulase Staphylococci and $45^{\circ} \mathrm{C}$ thermotolerant coliforms were within the limits established by law. No presence of Salmonella was detected. It was found a $44.30 \%$ moisture content, $0.36 \%$ ash, $29.68 \%$ fat, $1.68 \%$ fiber, $13.02 \%$ protein, $10.95 \%$ carbohydrate and a total of $366.42 \mathrm{kcal} / 100 \mathrm{~g}$. The Acceptability Index (AI) to the overall impression was greater than $70 \%$, giving this product a satisfactory sensory acceptance.

Keywords: Orange cream. Physical-chemical quality. Microbiological evaluation.

Sensory analysis.

\section{INTRODUÇÃO}

Os cremes de padarias com vida de prateleira média apresentaram crescimento importante nas últimas décadas. Os ingredientes inovadores têm proporcionado novas alternativas como a produção de diferentes sabores, maior digestibilidade e maior valor nutritivo.

Os benefícios da inclusão da laranja na dieta alimentar são inúmeros, em função do seu elevado valor nutricional, alto índice de fibras, água e vitaminas.

As panificadoras e confeitarias possuem um mercado cada vez mais exigente e disputado. Os consumidores estão preocupados com a saúde e o bem estar, dando preferência para alimentos de qualidade e com maior valor nutricional. Assim, quanto maior a diversificação de produtos e serviços, maior a probabilidade da empresa se sobressair frente a seus concorrentes.

Desta forma, a proposta deste estudo foi a elaboração de um creme de laranja com controle de qualidade adequado, avaliar sua aceitabilidade, sua qualidade microbiológica e determinar o valor nutricional para que este possa ser utilizado com fins comerciais pelas padarias e confeitarias da região.

\section{FUNDAMENTAÇÃO TEÓRICA}

A citricultura tem importante destaque econômico na agroindústria brasileira. Segundo Turra et al. (2014) o Brasil é o maior produtor de citros e também o maior produtor e exportador de suco de laranja, principal produto da cadeia citrícola.

Aproximadamente $98 \%$ de toda a colheita industrializada é representada por laranjas, limões, toranjas e tangerinas, sendo as laranjas os frutos mais relevantes por 
apresentar aproximadamente 82\% do total do processamento. Em 2013 a produção de laranjas no Brasil ultrapassou 17 mil toneladas (CRIZEL, 2013; FAO, 2013).

O suco de laranja contém vitamina $\mathrm{C}$, folato, potássio, cartotenóides, flavonóis, fibras e consumo estão associados a efeitos benéficos à saúde humana como a prevenção de doenças crônico-degenerativas e o equilíbrio da microbiota intestinal. (DUQUE, 2014).

O estado do Rio Grande do Sul é um importante produtor de citros, sendo a cultura desenvolvida predominantemente por produtores de base familiar (EMBRAPA, 2013).

A citricultura gaúcha apresenta condições para a produção de frutos de excelente qualidade. Os citros apresentam boa coloração, formato e sabor, tanto para variedades tradicionais como para as novas cultivares sem sementes, cuja tendência, futuramente, é dominar o mercado das frutas, devido ao excelente clima. A produção de citros é desenvolvida em pequenas propriedades, com uma área média de pomar por propriedade em torno de 2 hectares (ha). Constata-se ainda, de maneira geral, um baixo uso de insumos químicos e de equipamentos mecanizados. Por outro lado, graças à diversificação existente, a utilização de adubação orgânica vem sendo uma prática bastante comum entre os agricultores. Esses e outros aspectos contribuem para que a citricultura gaúcha esteja mais próxima da sustentabilidade, além de ser um importante fator de geração de trabalho e renda (EMATER, 2011).

Segundo Bublitz et al. (2015) o aumento da diversificação tecnológica de produção citrícola é imprescindível, visando à melhoria da renda das pequenas e médias propriedades cultivadoras de citros da região Sul do Brasil, a fim de que estas não se tornem tão dependentes apenas da produção de laranja no mercado consumidor.

Este trabalho teve por objetivo elaborar um creme de laranja com controle de qualidade adequado, para isto foram avaliadas suas características microbiológicas, sensoriais e de valor nutricional para que este possa ser utilizado pelas padarias e confeitarias da região. 


\section{METODOLOGIA}

\subsection{Obtenção do creme de laranja}

A pesquisa foi realizada nos Laboratórios de Tecnologia de Alimentos e de Bromatologia da Universidade de Santa Cruz do Sul - RS, no período de abril de 2015 a janeiro de 2016.

O suco foi obtido do bagaço da laranja Valência (Citrus sinensis L. Osbeck). As laranjas utilizadas são de produção local e foram adquiridas em um supermercado do município de Santa Cruz do Sul, Rio Grande do Sul (RS). Para a formulação do creme foram utilizados os seguintes ingredientes, também adquiridos no comércio local: açúcar, gemas, gelatina em pó incolor, manteiga e creme de leite.

As laranjas utilizadas para este experimento foram lavadas em água corrente, sanitizadas com hipoclorito de sódio na concentração de $150 \mathrm{mg} \cdot \mathrm{kg}^{-1}$ durante 15 minutos e, em seguida, as frutas foram novamente lavadas em água corrente. Posteriormente, utilizando ralador de aço inox, ralou-se as cascas até atingir aproximadamente 3 1/2 colheres de sopa de raspas de casca de laranja, e estas foram reservadas. Com o uso de extrator de suco industrial (Fundiferro FE002 Inox), foram produzidos $300 \mathrm{~mL}$ de suco de laranja. Os ingredientes como o açúcar, o suco de laranja e as gemas coadas foram levados ao fogo em banho-maria e misturados para homogeneização, até atingir aproximadamente $80^{\circ} \mathrm{C}$. Fora do fogo, foram acrescentadas as raspas de casca de laranja e a gelatina hidratada conforme a orientação do fabricante, misturando até a completa dissolução. A manteiga sem sal em pasta e o creme de leite foram adicionados por último, misturados até a homogeneização. Após, o creme foi colocado em vidro de conserva previamente esterilizado com tampa hermeticamente fechada, pasteurizado e posto em geladeira para adquirir a textura de gel e manter a sua conservação.

\subsection{Pasteurização}

Foi realizado um processo térmico de pasteurização em banho-maria com variações de tempo e temperatura, como segue: Tratamento $1: 75^{\circ} \mathrm{C}$ por 1 minuto (medida de temperatura interna do creme de $79^{\circ} \mathrm{C}$ ); Tratamento $2: 80^{\circ} \mathrm{C}$ por 30 segundos (medida da temperatura interna do creme de $84^{\circ} \mathrm{C}$ ).

\subsection{Testes físico-químicos}

Através da metodologia preconizada pelo Instituto Adolfo Lutz (2008) realizaram-se as análises da composição proximal do creme de laranja: umidade em estufa a $105^{\circ} \mathrm{C}$; cinzas com incineração dupla em bico de Bunsen e mufla $\left(550-600^{\circ} \mathrm{C}\right)$; 
fibra bruta pelo método de Weende; proteína pelo método de Kjeldahl (Valor de Correção de 6,25); lipídeos pelo método de Soxhlet. O carboidrato foi calculado pela diferença entre 100 e a soma das porcentagens de água, proteína, lipídios totais, fibras e cinzas. Para a realização do cálculo do valor calórico total, foram utilizados valores de conversão, alimento/energia, sendo 4, 9 e 4 para carboidratos, lipídios e proteínas respectivamente, e depois realizados o somatório desses valores (LEHNINGER, 2011). As análises da composição proximal do creme de laranja foram realizadas em quadruplicata e foi calculado o desvio-padrão dos resultados obtidos.

\subsection{Testes microbiológicos}

As análises microbiológicas de determinação de Salmonella sp., Contagem de Estafilococos Coagulase Positiva e Coliformes a $45^{\circ} \mathrm{C}(\mathrm{NMP} / \mathrm{g})$ foram realizadas após 2 meses de fabricação dos cremes de laranja que estavam armazenados em temperatura de refrigeração. As análises realizadas estão previstas na Resolução - RDC no 12, de 2 de janeiro de 2001(ANVISA, 2001), para este tipo de alimento. Todas as análises seguiram os métodos preconizados por Brasil (2003).

\subsection{Análise sensorial}

O creme de laranja obtido pela formulação foi submetido à análise sensorial com verificação dos atributos de cor, aroma, sabor, textura e aceitabilidade geral. A escala utilizada neste teste foi a de 9 (nove) pontos de acordo com Minim (2006), em que em escala decrescente: (9) gostei extremamente; (8) gostei moderadamente; (7) gostei regularmente; (6) gostei ligeiramente; (5) não gostei, nem desgostei; (4) desgostei ligeiramente; (3) desgostei regularmente; (2) desgostei moderadamente e (1) desgostei extremamente. Participaram da análise sensorial 43 julgadores não treinados que concordaram em assinar o Termo de Consentimento Livre e Esclarecido autorizado pelo Comitê de Ética e Pesquisa sob no 04991913.6.0000.5343.

\subsection{Tratamento estatístico}

Os resultados obtidos nas análises sensorial e proximal do creme foram submetidos ao programa estatístico SASM citado por Canteri et al. (2001) e teste de Tukey para verificação da existência de diferenças estatísticas entre as médias ao nível de $5 \%$ de significância. 


\section{RESULTADOS E DISCUSSÕES}

\subsection{Pasteurização}

O emprego do método de pasteurização é, geralmente, preferido quando outros tratamentos térmicos de temperatura mais elevada prejudicam as qualidades dos produtos (ARAÚJO, 2011).

O creme submetido às temperaturas de pasteurização não sofreu nenhum tipo de desestabilização da emulsão (Figura 1). A desestabilização da emulsão altera a textura que pode ser percebida pelo consumidor, o que pode afetar negativamente o nível de aceitação do produto.

\section{Figura 1- Cremes de laranja submetidos a diferentes temperaturas de pasteurização.}

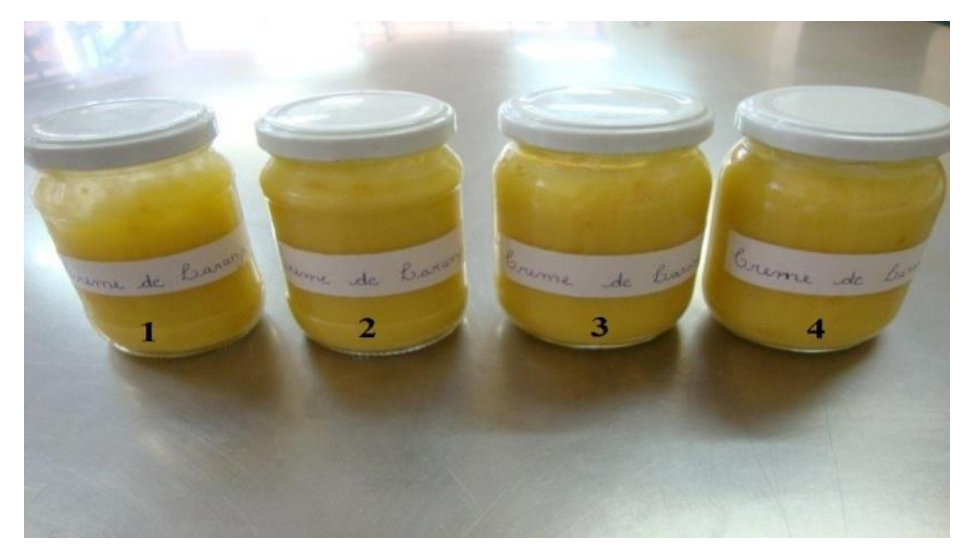

Figura 1. Potes 1 e 2 submetidos a temperatura de $75^{\circ} \mathrm{C}$ por 1 minuto. Potes 3 e 4 submetidos a temperatura de $80^{\circ} \mathrm{C}$ por 30 segundos.

Segundo Corsi (2007) misturas como emulsões ou espumas, que envolvem interfaces entre diferentes componentes, são responsáveis por uma série de percepções relacionadas à textura de vários alimentos. A estrutura de uma emulsão, em termos de volume de fases, diâmetro e cargas das gotículas da fase dispersa, resulta num determinado comportamento reológico e interações coloidais, que definem o comportamento da emulsão.

\subsection{Testes físico-químicos}

Os resultados referentes à composição proximal do creme de laranja para a avaliação das características nutricionais estão demonstrados na Tabela 1. Observa-se que o creme possui um alto índice de umidade com média de 44,30\%, parâmetro que 
deve ser considerado, pois a alta atividade de água facilita a deterioração e a contaminação microbiológica, o que pode dificultar a conservação (HAMACEK, 2013). Em relação ao resíduo inorgânico, o creme de laranja possui pouca quantidade, em média $0,36 \%$ de cinzas, porém, por volatilização, alguns minerais podem ter sido perdidos durante o processo de determinação em mufla à $550^{\circ} \mathrm{C}$.

Tabela 1 - Composição proximal do creme de laranja

\begin{tabular}{cc}
\hline Determinações $(\%)$ & Média \pm DP \\
\hline Umidade & $44,30 \pm 0,09$ \\
Cinzas & $0,36 \pm 0,04$ \\
Lipídios & $29,68 \pm 1,32$ \\
Fibras & $1,68 \pm 0,35$ \\
Proteínas & $13,01 \pm 0,55$ \\
Carboidratos & $10,95 \pm 1,21$ \\
Kcal $(100 \mathrm{~g})$ & $366,42 \pm 3,03$ \\
\hline
\end{tabular}

Como o creme é composto por manteiga e creme de leite, seu teor de lipídios é consideravelmente alto, em torno de $29,68 \%$. Porém, em se tratando de um produto para confeitarias, o creme de laranja é semelhante a outros recheios usados para tortas e bolos, como o Creme de manteiga, com composição básica de gemas, açúcar e manteiga sem sal, e como o Creme ligeiro, com composição básica de leite, açúcar, gemas e creme de leite batido. De forma simplificada, os cremes são preparações elaboradas a partir de derivados lácteos, gorduras e ovos, por isso, são produtos delicados, e se não forem conduzidas as Boas Práticas de Fabricação, alterações químicas como a oxidação podem ocorrer. Isso modificaria o resultado final da elaboração, como por exemplo, o sabor alterado pelo ranço, já que o creme possui um alto teor de gordura (BRANDÃO E LIRA, 2011).

O teor de fibras apresentado foi de 1,68\%, valor esse devido à presença de raspas da casca da laranja, rica em fibras solúveis, como a pectina (RUVIARO, 2008). Entretanto, segundo ANVISA (2012) neste caso, para ser fonte de fibras o alimento precisa conter pelo menos 2,5 gramas de fibras/porção e para ser rico mínimo de 5 gramas/porção. As recomendações de ingestão deste nutriente alimentar na dieta variam de acordo com a idade, o sexo e o consumo energético, sendo a recomendação adequada 
em torno de $14 \mathrm{~g}$ de fibra para cada $1.000 \mathrm{kcal}$ ingeridas (INSTITUTE OF MEDICINE, 2005). As proteínas do creme de laranja $(13,01 \%)$ provém das gemas,da gelatina e do creme de leite, e estas além da função nutricional, também ajudam nas propriedades organolépticas e na textura do alimento (CECCHI, 2003).

Segundo Sousa et al. (2007) a gema do ovo possui proteínas de alto valor biológico, ácidos graxos essenciais, fosfolipídeos e glicerol de ampla aplicação industrial e biomédica. A gema possui propriedades funcionais como emulsificação, coagulação e gelatinização, são responsáveis pela estrutura e estabilidade de maioneses, cremes e molhos para saladas. A gelatina é uma proteína totalmente desnaturada, deste modo, pode ser utilizada na indústria de alimentos apenas como agente emulsificante e não com finalidade nutritiva. A principal característica da gelatina é formar soluções para produzir géis estáveis abaixo de $40^{\circ} \mathrm{C}$. A aplicação da gelatina na área alimentar, fotográfica, cosmética e farmacêutica é baseada principalmente em suas propriedades gelificantes (GÓMEZ-GUILLÉN et al., 2011).Os carboidratos e as calorias completam o valor nutricional com média de $10,95 \%$ e $366,42 \mathrm{Kcal} / 100 \mathrm{~g}$, respectivamente. O açúcar adicionado à formulação é uma fonte de carboidrato com alto índice glicêmico e a gordura utilizada (manteiga e creme de leite) foram os ingredientes mais significativos que aumentaram o teor de calorias do creme de laranja (PHILIPPI, 2003).

\subsection{Testes microbiológicos}

Os resultados apresentados nas Tabelas 2 demonstram que os produtos elaborados encontram-se dentro dos padrões preconizados pela Resolução - RDC n ${ }^{\circ} 12$, de 2 de janeiro de 2001 (ANVISA, 2001), sendo desta forma considerados aptos para o consumo, mesmo depois de dois meses de vida de prateleira em temperatura de refrigeração.

Os coliformes totais e fecais tendem a colonizar o trato intestinal de animais de sangue quente, incluindo os humanos e podem contaminar os alimentos por meio de falhas em relação à higiene durante o processamento (SILVA JR, 2014). Já, a Salmonella pode estar presente em frutos e outros alimentos, dada a possibilidade do contato com matéria fecal animal durante seu cultivo (AGÊNCIA PORTUGUESA DE SEGURANÇA ALIMENTAR, 2004). Estes microrganismos são considerados microrganismos indicadores e sugerem a presença de agentes patogênicos. Os microrganismos indicadores associados às práticas de higiene incluem, entre outros, 
aeróbios mesófilos, coliformes termossensíveis e termotolerantes, e Staphylococcus coagulase positiva (LUES; VAN TONDER, 2007).

Tabela 2 - Resultados das análises microbiológicas dos cremes submetidos à temperatura de pasteurização de $7^{\circ} \mathrm{C}$ por 1 minuto e à temperatura de $80^{\circ}$ por 30 segundos.

\begin{tabular}{cccc}
\hline & \multicolumn{2}{c}{ Resultados } & \\
\hline Ensaio (s) & Resultado (s) & Unidade & VMP \\
$\begin{array}{c}\text { Contagem de Estafilococos } \\
\text { Coagulase Positiva }\end{array}$ & $<1,0 \times 10^{2}$ & UFC/g (Estimado) & $1,0 \times 10^{3}$ UFC/g \\
$\begin{array}{c}\text { NMP de Coliformes } \\
\text { Termotolerantes (45 })\end{array}$ & $<3,0 \times 10^{0}$ & NMP/g & $1,0 \times 10^{2}$ NMP/g \\
Pesquisa de Salmonella & Ausência em 25g & Ausência em 25g \\
\hline $\begin{array}{l}\text { Legenda: VMP (Valor Máximo Permitido), UFC (Unidades Formadoras de Colônias), NMP (Número } \\
\text { Mais Provável) }\end{array}$
\end{tabular}

A partir dos resultados das análises microbiológicas observou-se que o creme foi obtido com Boas Práticas de Fabricação, atendendo os padrões microbiológicos exigidos na legislação, fazendo com que a metodologia empregada fosse efetiva na prevenção do desenvolvimento microbiano, pois os valores encontrados ficaram dentro dos parâmetros estabelecidos pela Resolução vigente. Normalmente as contaminações podem estar associadas às condições de preparo no que se refere às questões higiênicosanitárias, tanto quanto a contaminação prévia da matéria-prima, devido ao seu mal acondicionamento, diferentes tecnologias utilizadas, teor de umidade, entre outros (GOMES, 2008).

\subsection{Análise sensorial}

O creme de laranja formulado foi submetido à análise sensorial e seus resultados estão demonstrados na Tabela 3. 
Tabela 3 - Média dos valores dos atributos organolépticos do creme de laranja

\begin{tabular}{cc}
\hline TRATAMENTO & MÉDIA \\
\hline COR & $8,069^{\mathrm{a}}$ \\
AROMA & $7,837^{\mathrm{a}}$ \\
SABOR & $7,837^{\mathrm{a}}$ \\
TEXTURA & $7,790^{\mathrm{a}}$ \\
ACEITAÇÃO GLOBAL & $7,883^{\mathrm{a}}$ \\
\hline * Letras iguais na mesma linha representam resultados estatisticamente iguais, e letras diferentes \\
representam diferença significativa pelo teste de Tukey (p < 0,05).
\end{tabular}

A nota mais baixa foi de 7,79 (86,55\% de aceitação) na escala hedônica de 9 pontos para a textura do creme, o que equivale a um julgamento entre "gostei muito" e "gostei moderadamente" e a nota mais alta foi de 8,06 (89,85\% de aceitação) para a cor, equivalente a "gostei muito". A aceitação global, representando todas as características organolépticas do produto foi avaliada com 87,58\% de aceitação. De acordo com Almeida, Feijó, Marceline 2016, para uma boa repercussão o índice de aceitação deve ser superior a 70\%. Desse modo, podemos afirmar que em relação à impressão global, o creme teve boa aceitação, indicando potencial para compra entre os consumidores.

\section{CONCLUSÕES}

O presente estudo denotou que há viabilidade para produção e comercialização do creme de laranja devido a sua simplicidade de preparo, manutenção de propriedades funcionais e qualidade higiênico sanitária. O Índice de Aceitabilidade (IA) para a impressão global foi superior a 70\%, aferindo aceitação sensorial satisfatória.

O aproveitamento das frutas cítricas em novos produtos é uma oportunidade para os pequenos e médios produtores da citricultura diversificar suas culturas, reduzindo assim desperdícios e gerando aumento de renda.

\section{REFERÊNCIAS}

AGÊNCIA NACIONAL DE VIGILÂNCIA SANITÁRIA. Resolução RDC no 12, de 02 de janeiro de 2001. Aprova regulamento técnico sobre os padrões microbiológicos de alimentos, em anexo. Diário Oficial da República Federativa do Brasil, Brasília, 10 jan. 2001. Acesso em: 10 jan. 2016. 
AGÊNCIA NACIONAL DE VIGILÂNCIA SANITÁRIA. Ministério da Saúde. Resolução $\mathrm{n}^{\circ}$ 54. Dispõe sobre o Regulamento Técnico sobre Informação Nutricional Complementar. Diário Oficial da União, Brasília, 12 de nov. 2012.

AGÊNCIA PORTUGUESA DE SEGURANÇA ALIMENTAR. Regulamento (CE) n. 852/2004. Parlamento Europeu. Conselho da União Europeia Jornal Oficial das Comunidades Europeias L 139:5555, 04-29, 2004. Disponível em: <http://www.factorsegur.pt/segalimentar/legislacao/Carnes/Reg\%20853-2004.pdf.> Acesso em: 21 de ago 2016.

ALMEIDA, I. L. G. T.; FEIJÓ, M. B. S.; MARCELLINI, P. S. Desenvolvimento, caracterização e aceitação de brownie de biomassa de fruta-pão verde. Jornal of Health Sciences, n. 2, v. 18, 2016.

ARAÚJO, W. M. C. (Org.). Alquimia dos alimentos. 2. ed., rev. e ampl. Brasília: SENAC-DF, 2011. 496 p.

BUBLITZ, S. et al. Produção e caracterização fisíco-química de farinhas de mandarina verde orgânica (citrus reticulata). Revista Jovens Pesquisadores, Santa Cruz do Sul, n.1, v.5, p.2-10, 2015.

BRANDÃO, S. S.; LIRA H. L. de. Tecnologia de Panificação e Confeitaria. Recife: EDUFRPE, 2011. 148 p.

BRASIL. Ministério da Agricultura, Pecuária e Abastecimento. Departamento de Inspeção de Produtos de Origem Animal. Instrução Normativa nº 62, de 26 de agosto de 2003. Oficializa os Métodos Analíticos Oficiais para Análises Microbiológicas para Controle de Produtos de Origem Animal e Água. Diário Oficial da República Federativa do Brasil. Brasília, 18 set. 2003, Seção I, p.14

CANTERI, M. G. et al. SASM- Agri - Sistema para análise e separação de médias em experimentos agrícolas pelos métodos Scott-Knott, Tukey e Duncan. Revista Brasileira de Agrocomputação, Ponta Grossa, n. 2, v. 1, p. 18-24, dez. 2001.

CECCHI, H. M. Fundamentos teóricos e práticos em análise de alimentos. 2. ed., Revista Campinas: Universidade de Sorocaba - Rede de Avaliação Institucional de Educação Superior, 2003.

CORSI, A. et al. Interface stability and copolymers: application to food systems. Food Hydrocolloids, Oxford, v. 21, p. 870-878, 2007.

CRIZEL, T. de. M. Aproveitamento dos subprodutos da indústria de suco der laranja para aplicação em alimentos. 2013. Dissertação (Programa de Pós-Graduação em Ciência e Tecnologia de Alimentos - Mestrado e Doutorado) Universidade Federal do Rio Grande do Sul, Porto Alegre, 2013.

DUQUE, A. L. R. F.; MONTEIRO, M.; SIVIERI, K. Potencial do suco de laranja na modulação da microbiota intestinal humana. Alimentos e nutrição, Araraquara, n. 1, v.25, 2014. 
EMATER. Empresa de Assistência Técnica e Extensão Rural. Detalhe notícia, 2011. Disponível em: $\quad$ http://www.emater.tche.br/site/noticias/detalhenoticia.php?id=12566\#.V7ot9vkrLIU $>$. Acesso em 27 jan. de 2016.

EMBRAPA. Empresa Brasileira de pesquisa Agropecuária. Plantas de Cobertura e Adubação Verde para Citros, 2013. Disponível em: <http://ainfo.cnptia.embrapa.br/digital/bitstream/item/135173/1/Documento-383-Comcapa.pdf $>$. Acesso em 27 jan. de 2016.

FOOD AND AGRICULTURE ORGANIZATION - FAO. Statistical Yearbook 2013. Disponível em: 〈http://www.fao.org/docrep/018/i3107e/i3107e.PDF>. Acesso em: jan. 2016.

GOMES, E. C.; NEGRELLE, R. R. B.; ELPO, E. R. S. Determinação da qualidade microbiológica e físico-química de chás de Cymbopogom citratus (D.C) Stapf (capimlimão). Acta Scientiarum. Health Sciences, n. 1, v.30, p. 47-54, mar. 2008.

GÓMEZ-GUILLÉN, M. C.; GIMÉNEZ, B.; LÓPEZ-CABALLERO, M. E.; MONTERO, M. P. Functional and bioactive properties of collagen and gelatin from alternative sources: A review. Food Hydrocolloids, n. 8, v.25, p. 1813-1827, 2011.

HAMACEK, F. R. et al. Valor nutricional, caracterização física e físico-química de jenipapo (Genipa americana L.) do cerrado de Minas Gerais. Alimentos e Nutrição, Araraquara, n. 1, v. 24, p. 78, 2013.

INSTITUTO ADOLFO LUTZ- IAL. Normas analíticas do Instituto Adolfo Lutz. São Paulo, 2008.

INSTITUTE OF MEDICINE. Dietary Reference Intakes: Energy, Carbohydrate, Fiber, Fat, Fatty Acids, Cholesterol, Protein, and Amino Acids. Washington, D.C., National Academies Press, 2005.

LEHNINGER, A. L.; NESON, D. L.; COX, M. M. Princípios de bioquímica. 5 ed. Porto Alegre: Artmed, 2011.

MINIM, V. P. R. Análise sensorial: estudos com consumidores. Universidade Federal de Viçosa, 2006.

LUES, J. F.; VAN TONDER, I. The occurrence of indicator bacteria on hands and aprons of food handlers in the delicatessen sections of a retail group. Food Control, n.4, v. 18, p. 326-332, 2007.

PHILIPPI, S. T. Nutrição e técnica dietética. 1. ed. Barueri: Manole, 2003. 390 p.

RUVIARO, L. et al. Análise sensorial de sobremesa acrescida a farelo de casca e bagaço de laranja entre universitários de Guarapuava (PR). Revista Salus, n. 2, v. 2, p. 41- 50, jul/dez. 2008.

SILVA JUNIOR, E. A. Manual de Controle Higiênico-Sanitário em Serviços de alimentação. 7. ed. São Paulo: Editora Varela, 2014. 
SOUSA, R. de C. S. et al. Effect of $\mathrm{pH}$ and salt concentration on the solubility and density of egg yolk and plasma egg yolk. Food Science Technology, n. 7, v. 40, p.12531258, 2007.

TURRA, C. et al. Overview of the Brazilian Citriculture Certification. Journal of Agricultural and Environmental Ethics, n. 4, v. 27, p. 663-679, 2014.

\section{Como citar este documento:}

SCHUCK, Heloisa et al. Desenvolvimento de um creme de laranja e avaliação da qualidade físico-química, microbiológica e sensorial. Revista Jovens Pesquisadores, Santa Cruz do Sul, v. 6, n. 2, nov. 2016. ISSN 2237-048X. Disponível em: <https://online.unisc.br/seer/index.php/jovenspesquisadores/article/view/7299>. Acesso em: ... doi:http://dx.doi.org/10.17058/rjp.v6i2.7299. 